\title{
The potential of automated corrective feedback to remediate cohesion problems in advanced students' writing
}

\author{
Carola Strobl ${ }^{1}$
}

\begin{abstract}
This study explores the potential of a feedback environment using simple string-based pattern matching technology for the provision of automated corrective feedback on cohesion problems. Thirty-eight high-frequent problems, including non-target like use of connectives and co-references were addressed providing both direct and indirect feedback. Advanced students of German as a foreign language (L2) $(n=36)$ received this feedback on summary writing in three subsequent sessions. Their revision activities were analysed for a ratio per 100 words and success rate, and their attitudes towards the feedback were investigated using questionnaires. The results show that automated feedback based on pattern matching has the potential to remedy over- and under-use of connectives and co-reference devices. Furthermore, although participants preferred direct feedback, the revision rate was higher with indirect metacognitive feedback providing grammar explanations.
\end{abstract}

Keywords: automated feedback, advanced writing, cohesion, human computer interaction.

\section{Introduction}

Cohesion in written learner language is an important, yet under-researched area of investigation. L2 learners struggle with cohesion even at advanced levels of mastery. Cohesion can be expressed through a broad range of lexico-grammatical devices (Halliday \& Hasan, 1976). Different lexico-grammatical preferences between the L2 and their mother tongue (L1) can cause L2 writers to make nontarget like choices of cohesive features. Furthermore, the pedagogical approach

1. Ghent University, Ghent, Belgium; carola.strobl@ugent.be

How to cite this article: Strobl, C. (2017). The potential of automated corrective feedback to remediate cohesion problems in advanced students' writing. In K. Borthwick, L. Bradley \& S. Thouësny (Eds), CALL in a climate of change: adapting to turbulent global conditions - short papers from EUROCALL 2017 (pp. 294-299). Research-publishing.net. https://oi.org/10.14705/rpnet.2017.eurocall2017.729 
towards cohesion in L2 textbooks has been identified as harmful, as it is frequently characterised by a focus on grammatical accuracy, rather than on stylistic appropriateness (Cho \& Shin, 2014). It is therefore timely to develop pedagogic support that addresses cohesion problems in learner writing in a more appropriate way.

Automated feedback on L2 writing has long been applied mainly to address grammar, lexical, and/or mechanical issues in lower-level instruction. It is only recently that automated writing evaluation systems for English have adopted technologies that allow for a more sophisticated analysis of, and feedback on, learner writing with regard to cohesion (Crossley, Kyle, \& McNamara, 2016). For German, no such tool has been developed yet.

This explorative study investigates the potential of a tool using simple pattern matching technology for the provision of corrective feedback on cohesion problems. It also adds to the debate about the effectiveness of written corrective feedback in electronic writing environments (Bitchener, 2012; Ene \& Upton, 2014). It was driven by the following research questions: (1) Can cohesion problems successfully be addressed through automated feedback based on pattern-matching technology? (2) Does direct or indirect feedback trigger a higher amount of (successful) revisions? (3) What are students' attitudes towards this feedback?

\section{Method}

\subsection{Feedback creation}

The environment used for this study was developed at Ghent University (Belgium) for electronic teacher feedback. Among other features, this tool allows for the automated lookup of words and utterances in predefined lists, highlighting matches in students' texts. By hovering over the highlighted words, additional information can be visualised. This feature was used in the study to provide automated feedback regarding potential non-target like use of cohesion devices. As cohesion is context bound by its very nature, the absence of context-sensitive lookup options and of Natural Language Processing (NLP) technologies for linguistic analysis posed a major challenge. Therefore, the feedback messages were formulated as non-directive suggestions inviting students to reflect their choice of cohesive devices. 
To establish a list of potential cohesion problems in summary writing (the assignment used), a corpus of 72 summaries written by a comparable cohort of students to the participants in the study was scrutinised. Thirty-eight high-frequent problems emerged that can be identified through string-based pattern-matching. They mainly concern the non-target like use of connectives and co-reference devices. To target those 38 problems, 125 list entries were created covering morphological and lexical variations of the words or utterances involved. Three lists were produced, each conveying a different type of feedback: (1) direct feedback providing a suggestion for correction of the potential problem (DF), (2) indirect metacognitive feedback providing a grammar explanation (IF1), and (3) indirect feedback providing example utterances (IF2).

\subsection{Study design and data collected}

Thirty-six students of an intact writing class took part in the experiment. All participants have Dutch as their L1 and major in German L2, with a medium advanced writing proficiency level $^{2}$. Prior to the experiment, they received instruction on summary writing, with a focus on the use of cohesive devices. They also had one session to familiarise with the feedback tool.

The participants received automated feedback on three summaries. On the first occasion, DF was provided, followed by indirect feedback in the two subsequent occasions. To avoid a sequencing effect, half of the group received first IF1 and then $\mathrm{IF}^{3}$, and the other half vice-versa. Quantitative data of the revision activities were obtained through comparison of drafts before and after self-correction, and changes were coded according to successfulness. Furthermore, two questionnaires were administered to evaluate participants' attitudes.

\section{Results and discussion}

\subsection{Revision rate and success by feedback type}

Figure 1 displays the quantitative results of the revision analysis. To account for differences in word count in the three conditions, revisions per 100 words were calculated. IF1 triggered most revisions by far, totalling two and two and a half times the amount of DF and IF2, respectively. Furthermore, the success rate of

\footnotetext{
2. B2-C1 on the common european framework of reference for languages scale

3. See feedback examples: https://research-publishing.box.com/s/4ebxytqv 1 crnxm185ij5ilboc9ubv53q
} 
revisions was higher following IF2 (74\% of all changes induced by this feedback type) than following DF (64\%) and IF1 (61\%) ${ }^{4}$. These findings are not in line with the results of earlier studies on electronic (human) feedback on complex L2 writing that ascribed a higher success rate to direct, explicit feedback (c.f. Ene \& Upton, 2014, p. 89).

Figure 1. Revision rate and success by feedback type

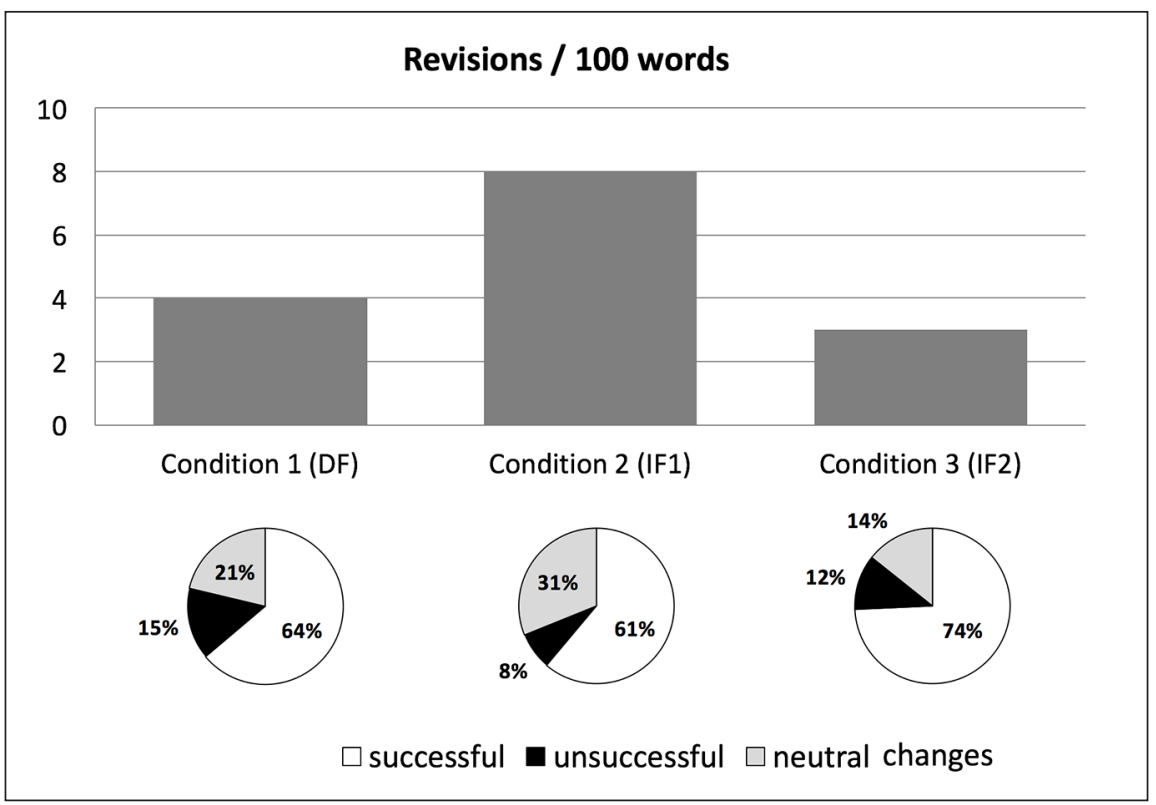

\subsection{Students' attitudes towards the feedback}

Three results obtained from the questionnaires will be discussed here. They concern (1) preferences for feedback type, (2) overall attitudes towards usefulness of the automated feedback, and (3) attitudes with regard to the unnecessary feedback created due to lack of sophisticated technology.

(1) Contrary to expectations based on the amount of revisions, students did not prefer indirect feedback based on grammar explanations, which actually received the lowest preference score $(28 \%)$, followed by indirect feedback based on

4. See revision examples: https://research-publishing.box.com/s/4ebxytqv1 crnxml85ij5ilboc9ubv53q 
examples (31\%). Students' comments comparing the two indirect feedback can be interpreted as windows to their preferred learning styles, i.e. inductive learning ("I like to deduce rules from examples; grammar explanations are tedious") versus deductive learning ("I prefer an explanation because I want to know why things are wrong"). The majority of students, however, preferred direct feedback (41\%).

(2) Overall, students were positive with regard to the feedback received, rating the usefulness for self-correction in the concrete assignment $3(50 \%)$ or $4(41 \%)$ on a Likert scale of 5 ( $1=$ not useful, $5=$ very useful). Furthermore, $71 \%$ of the students declared they would like to use the tool in self-directed study mode to revise their bachelor papers. Regarding the usefulness of the feedback as a tool to raise awareness for potential problems in their writing in general, the satisfaction scores were even higher: 3 (24\%), 4 (53\%), and 5 (15\%). Indeed, students declared to look at their written texts "with different eyes" after having received automated feedback on cohesion three times in a row. This suggests that the feedback was helpful to increase their noticing ability (Schmidt, 1990), which is important for the development of learner autonomy.

(3) As mentioned above, one of the main challenges in the study design was the lack of context-sensitive lookups which lead to a high amount of unnecessary highlighting of words and utterances that actually were well formulated. As this might have a potentially overwhelming effect, it was important to elicit students' attitudes about this aspect. Interestingly, only $6 \%$ of the students rated the unnecessary feedback annoying ( 4 on a Likert scale ranging from $1=$ not annoying at all to $5=$ very annoying), while $15 \%$ felt not annoyed at all ( 1 on Likert scale). The majority rated their degree of annoyance as $3(47 \%)$ or $2(35 \%)$.

\section{Conclusions}

This explorative study provided evidence that cohesion problems can successfully be addressed through automated feedback. Simple pattern-matching technologies in combination with tentatively formulated suggestions can help students to remediate over- and under-use of connectives and co-reference devices. While students preferred direct feedback, indirect feedback proved to be more successful for revision, with grammar explanations triggering a higher amount of revisions, and example utterances leading to a higher rate of successful revisions. These findings add to our understanding about the effectiveness of written corrective feedback, adding non-directive automated feedback as a new, under-researched setting. Perhaps even more important than revision success, students reported that 
the repeated provision of feedback through highlighting potentially problematic words and utterances increased their noticing. These promising results indicate that automated feedback on cohesion is a path worth further exploration. For future tool development, implementing NLP for linguistic and semantic analysis should be considered. This way, the range of cohesive devices to be addressed can be expanded and unnecessary feedback can be avoided.

\section{References}

Bitchener, J. (2012). A reflection on 'the language learning potential' of written CF. Journal of Second Language Writing, 21(4), 348-363. https://doi.org/10.1016/j.jslw.2012.09.006

Cho, H. Y., \& Shin, J.-A. (2014). Cohesive devices in English writing textbooks and Korean learners' English writings. English Teaching, 69(1), 41-59.

Crossley, S. A., Kyle, K., \& McNamara, D. (2016). The tool for the automatic analysis of text cohesion (TAACO): automatic assessment of local, global, and text cohesion. Behavior Research Methods, 48(4), 1227-1237. https://doi.org/10.3758/s13428-015-0651-7

Ene, E., \& Upton, T. A. (2014). Learner uptake of teacher electronic feedback in ESL composition. System, 46, 80-95. https://doi.org/10.1016/j.system.2014.07.011

Halliday, M. A. K., \& Hasan, R. (1976). Cohesion in English. Longman.

Schmidt, R. (1990). The role of consciousness in second language learning. Applied Linguistics, 11, 129-158. 


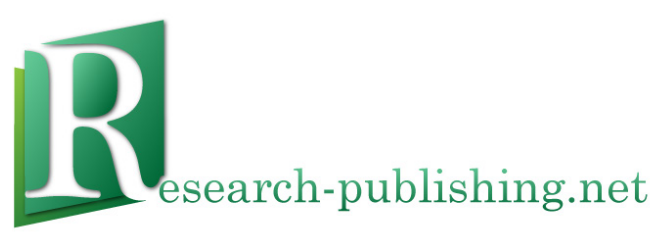

Published by Research-publishing.net, not-for-profit association Contact: info@research-publishing.net

(C) 2017 by Editors (collective work)

(C) 2017 by Authors (individual work)

CALL in a climate of change: adapting to turbulent global conditions - short papers from EUROCALL 2017 Edited by Kate Borthwick, Linda Bradley, and Sylvie Thouësny

Rights: This volume is published under the Attribution-NonCommercial-NoDerivatives International (CC BY-NC-ND) licence; individual articles may have a different licence. Under the CC BY-NC-ND licence, the volume is freely available online (https://doi.org/10.14705/rpnet.2017.eurocall2017.9782490057047) for anybody to read, download, copy, and redistribute provided that the author(s), editorial team, and publisher are properly cited. Commercial use and derivative works are, however, not permitted.

Disclaimer: Research-publishing.net does not take any responsibility for the content of the pages written by the authors of this book. The authors have recognised that the work described was not published before, or that it was not under consideration for publication elsewhere. While the information in this book are believed to be true and accurate on the date of its going to press, neither the editorial team, nor the publisher can accept any legal responsibility for any errors or omissions that may be made. The publisher makes no warranty, expressed or implied, with respect to the material contained herein. While Research-publishing.net is committed to publishing works of integrity, the words are the authors' alone.

Trademark notice: product or corporate names may be trademarks or registered trademarks, and are used only for identification and explanation without intent to infringe.

Copyrighted material: every effort has been made by the editorial team to trace copyright holders and to obtain their permission for the use of copyrighted material in this book. In the event of errors or omissions, please notify the publisher of any corrections that will need to be incorporated in future editions of this book.

Typeset by Research-publishing.net

Cover design based on (C) Josef Brett's, Multimedia Developer, Digital Learning, http://www.eurocall2017.uk/, reproduced with kind permissions from the copyright holder.

Cover layout by (C) Raphaël Savina (raphael@savina.net)

Photo "frog” on cover by (C) Raphaël Savina (raphael@savina.net)

Fonts used are licensed under a SIL Open Font License

ISBN13: 978-2-490057-04-7 (Ebook, PDF, colour)

ISBN13: 978-2-490057-05-4 (Ebook, EPUB, colour)

ISBN13: 978-2-490057-03-0 (Paperback - Print on demand, black and white)

Print on demand technology is a high-quality, innovative and ecological printing method; with which the book is never 'out of stock' or 'out of print'.

British Library Cataloguing-in-Publication Data.

A cataloguing record for this book is available from the British Library.

Legal deposit: Bibliothèque Nationale de France - Dépôt légal: décembre 2017. 